\title{
Rate of Return Risk pada Perbankan Syariah di Indonesia
}

\author{
Hendra Cipta \\ Fakultas Syariah dan Ekonomi Islam \\ IAIN Syaikh Abdurrahman Siddik Bangka Belitung, Indonesia \\ hendracipta@iainsasbabel.ac.id
}

\begin{abstract}
The rate of return risk is one of the risks that Islamic banks in Indonesia should pay attention to. The purpose of this research is to predict the factors that affect the rate of return risk of Islamic banking in Indonesia (namely Islamic Commercial Banks and Sharia Business Units) from 2015 to 2019. The research methodology used is multiple regression with the EViews data processing application. version 9. The results of this study found that the deposit variable has a significant positive effect on the rate of return risk, while the BI-rate variable does not effect on the rate of return risk of Islamic banks in Indonesia.

Rate of return risk merupakan salah satu risiko yang harus menjadi perhatian oleh bank syariah di Indonesia. Maksud dari penelitian ini adalah untuk memprediksi faktorfaktor yang mempengaruhi rate of return risk perbankan syariah di Indonesia (yaitu Bank Umum Syariah dan Unit Usaha Syariah) dari tahun 2015 sampai dengan tahun 2019. Metodologi penelitian yang digunakan adalah regresi berganda dengan aplikasi pengolah data EViews versi 9. Hasil penelitian ini menemukan bahwa variabel deposito mempunyai pengaruh signifikan positif terhadap rate of return risk sedangkan variabel BI-rate tidak berpengaruh terhadap rate of return risk bank syariah di Indonesia.
\end{abstract}

Keywords: Rate of Return Risk, Deposito, BI-rate

\section{A. Pendahuluan}

Risiko akan muncul ketika keputusan yang diambil tidak berdasarkan informasi yang sempurna, benar dan akurat. Jika keputusan yang diambil tidak diukur dengan kemungkinan risiko yang akan dihadapi dan keputusan yang diambil karena kedekatan emosional, maka sebenarnya keputusan yang diambil tersebut sedang membuka gerbang untuk masuknya risiko. Informasi yang tidak sempurna akan menghasilkan ketidakpastian. Sebenarnya dalam segala sisi kehidupan selalu ada ketidakpastian, sebagaimana firman Allah dalam surat Luqman (31) ayat 34. Berdasarkan ayat ini Allah berfirman bahwa manusia mustahil sudah mengetahui perihal rezekinya dan apa yang 
akan menimpanya esok hari, artinya terdapat ketidakpastian yang akan dihadapi pada esok harinya. ${ }^{1}$

Risiko pada perusahaan muncul ketika adanya ketidakpastian (uncertainty) yang "mengancam" profitabilitas perusahaan tersebut dan mengakibatkan kerugian bagi perusahaan tersebut. Dalam perspektif regulasi, suatu perusahaan (dalam hal ini perbankan) perlu menjaga kecukupan modalnya untuk menghadapi berbagai risiko (underlying philosophy of capital requirement). ${ }^{2}$

Risiko akan muncul ketika outcome yang diharapkan tidak diketahui, atau bisa juga dikatakan bahwa risiko akan muncul ketika ada volatilitas kemungkinan hasil yang tidak diharapkan. Setiap bisnis dan investasi akan selalu berhadapan dengan ketidakpastian. Institusi keuangan akan selalu berhadapan dengan risiko-risiko khusus yang berasal dari aktivitas mereka, karena tujuan dari institusi keuangan adalah untuk memaksimalkan keuntungan para pemilik saham.

Ada dua metode dalam mengklasifikasikan risiko, yaitu metode yang membandingkan antara risiko bisnis dan risiko keuangan. Risiko bisnis akan meningkat seiring dengan perkembangan bisnis perusahaan itu sendiri. Karena risiko bisnis ini adalah faktor yang mempengaruhi pemasaran produk. Sementara, risiko keuangan akan meningkat seiring dengan kerugian yang diderita dalam pasar keuangan. ${ }^{3}$

Risiko keuangan dapat meningkatkan profil risiko perbankan secara keseluruhan. Contohnya ketika bank berbisnis pada mata uang asing, maka kemungkinan bank tersebut akan kena dampak risiko mata uang, dan mungkin juga akan kena risiko likuiditas, kredit dan risiko repricing jika berada pada posisi open. Sementara itu risiko bisnis perbankan berhubungan dengan lingkungan bisnis perbankan termasuk faktor makroekonomi, kebijakan perusahaan, faktor regulator dan infrastruktur sektor keuangan perbankan seperti sistem payment. $^{4}$

\footnotetext{
${ }^{1}$ Imam Wahyudi and et.al., Manajemen Risiko Bank Islam (Jakarta: Salemba Empat, 2013).

2 Masyhud Ali, Manajemen Risiko: Strategi Perbankan Dan Dunia Usaha Menghadapi Tantangan Globalisasi Bisnis (Jakarta: PT. Raja Grafindo Persada, 2006).

3 Tariqullah Khan, Risk Management: An Analysis of Issuess in Islamic Financial Industry (Jeddah: Lembaga Pelatihan dan Riset Islamic Development Bank, 2001).

${ }^{4}$ Hennie Van et.al. Greuning, Risk Analysis for Islamic Banks (Washington: The World Bank, 2008).
} 
Risiko di perbankan syariah terkadang juga bisa muncul dari keputusan yang diambil oleh perbankan syariah itu sendiri. Sebagai ilustrasi, jika ada calon nasabah yang mengajukan permohonan pembiayaan. Ketika bank syariah memutuskan untuk menerima permohonan pembiayaan calon nasabah tersebut sebenarnya bank syariah sedang menghadapi risiko, dan ketika bank syariah memutuskan untuk menolak permohonan pembiayaan calon nasabah tersebut, sebenarnya bank syariah juga sedang menghadapi risiko. Ketika bank syariah menerima permohonan pembiayaan calon nasabah, bank syariah akan mengahadapi risiko ketika calon nasabah yang akan diberikan pembiayaan tidak amanah dan tidak profesional, sehingga bisa saja nasabah tersebut sengaja tidak mengangsur angsuran pembiayaan atau pembiayaan yang diberikan dipergunakan tidak sesuai dengan isi akad. Sementara ketika bank syariah menolak permohonan pembiayaan calon nasabah, bank syariah akan menghadapi risiko hilangnya calon nasabah yang potensial dan berkurangnya kuantitas nasabah di bank syariah tersebut. ${ }^{5}$

Salah satu risiko yang terdapat pada bank syariah yang beroperasi dengan prinsip bagi hasil adalah rate of return risk (risiko imbal hasil). Rate of return risk adalah risiko yang muncul sebagai akibat perubahan tingkat imbal hasil yang dibayarkan bank kepada nasabah funding (penabung dan deposan), karena terjadi perubahan tingkat imbal hasil yang diterima Bank dari penyaluran dana (pembiayaan yang disalurkan), risiko ini secara perlahan dapat mempengaruhi perilaku nasabah dana pihak ketiga. Risiko imbal hasil (Rate of Return Risk) adalah kemungkinan kerugian yang akan diderita oleh perbankan dikarenakan pergerakan imbal hasil di pasar riil berlawanan dengan transaksi perbankan ${ }^{6}$

Penelitian Oktariyani Wahyuningtyas menemukan bahwa rate of return risk (risiko imbal hasil) yang diproksikan kepada profit sharing berpengaruh terhadap return Dana Pihak Ketiga Bank Umum Syariah. Begitu juga dengan risiko investasi (yang diproksikan dengan Non Performing Financing Mudharabah) dan risiko likuiditas

\footnotetext{
${ }^{5}$ Wahyudi and et.al., Manajemen Risiko Bank Islam.

${ }^{6}$ Ahmad Ifham Sholihin, Buku Pintar Ekonomi Syari'ah (Jakarta: PT. Gramedia Pustaka Utama, 2010).
} 
| HENDRA CIPTA | Rate of Return RIsk...

(yang diproksikan dengan Financing to Deposit Ratio) juga berpengaruh terhadap Dana Pihak Ketiga Bank Umum Syariah. ${ }^{7}$

Zairy Zainol dan Salina H. Kassim menemukan bahwa total deposito bank Islam dan rate of return bank Islam berhubungan positif yang mengindikasikan risiko rate of return di bank Islam dimana deposan tertarik dengan rate of return yang tinggi dan dapat beralih atau menarik deposito mereka ketika rate of return menurun. Pada implementasinya di Malaysia (tempat penelitian ini dilakukan), di mana bank syariah beroperasi bergandengan tangan dengan bank konvensional (dual banking system), kedua sistem dapat berinteraksi mengingat bahwa mereka beroperasi dalam lingkungan ekonomi makro yang umum. Jika rate of return di bank-bank Islam dan suku bunga di konvensional bank dihubungkan, peningkatan suku bunga dapat mendorong bank Islam meningkatkan laba deposito mereka dalam rangka untuk menghindari masalah deposan mengalihkan deposito mereka ke bank-bank konvensional atau menarik dana mereka. Selain itu, tidak ada pembatasan dikenakan pada deposan dalam sistem perbankan ganda di Malaysia yang ingin memindahkan dana mereka dari satu sistem ke sistem lain yang juga bisa mengekspos bank ke masalah Displaced Commercial Risk (DCR). ${ }^{8}$

Heni Hasanah, Noer Azam Achsani, Ascarya dan Hermanto Siregar juga menemukan bahwa Displaced Commercial Risk terdapat di setiap Dana Pihak Ketiga bank syariah. Implikasi penting dari penelitian ini bagi manajemen bank syariah adalah agar mengamati fluktuasi interest rate dan faktor-faktor penentu lainnya, dan tidak hanya fokus pada rate of return bank syariah. Hasil lainnya adalah Displaced Commercial Risk terjadi pada nasabah kategori floating customer, maka langkah yang perlu dilakukan bank syariah adalah inovasi produk yang tetap memperhatikan kepatuhan syariah agar loyal customer meningkat. ${ }^{9}$

Data rate of return risk Bank Umum Syariah di Indonesia tahun 2015 sampai dengan tahun 2019 terus mengalami peningkatan. Hal ini terlihat pada data berikut ini:

${ }^{7}$ Oktariyani Wahyuningtyas, "Analisis Pengaruh Risiko Imbal Hasil, Risiko Investasi Dan Risiko Likuiditas Terhadap Return Dana Pihak Ketiga (Studi Pada Bank Umum Syariah),"Skipsi, Fakultas Ekonomi Dan Bisnis Islam UIN Sunan Kalijaga Yogyakarta (2017).

${ }^{8}$ Zairy Zainol and Salina H. Kassim, "An Analysis of Islamic Bank's Exposure to Rate of Return Risk," Journal of Economic Cooperation and Development 31, no. 1 (2010): 59-84.

${ }^{9}$ Heni Hasanah and et.al., "Displaced Commercial Risk: Empirical Analysis on The Competition between Conventional and Islamic Banking System in Indonesia," Advances in Natural and Applied Sciences 7, no. 3 (2013): 292-299. 
Gambar 1. Rate of Return Risk (Profit Sharing) pada Perbankan Syariah di Indonesia Tahun 2015-2019.

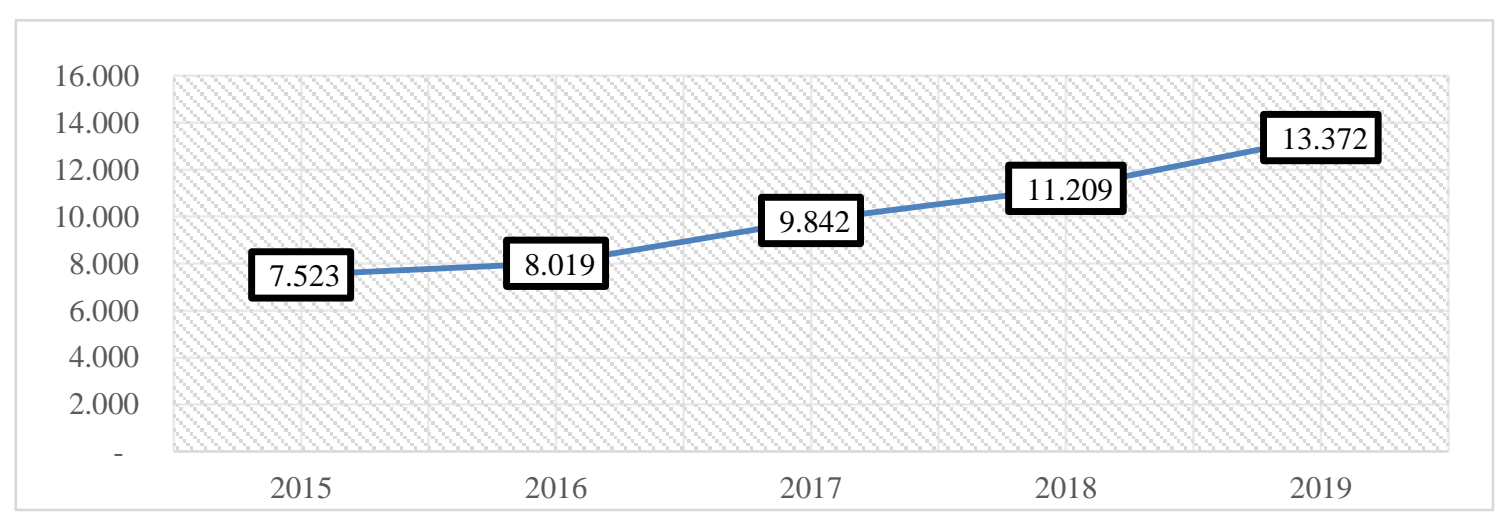

Sumber: OJK.go.id

Risiko-risiko yang dihadapi perbankan tersebut (termasuk bank syariah) sudah diantisipasi oleh perbankan dengan penerapan manajemen risiko ${ }^{10}$ sebagai bentuk kehati-hatian perbankan sebagaimana diwajibkan melalui Undang-undang Nomor 7 Tahun 1992 dan telah diubah dengan Undang-undang Nomor 10 Tahun 1998. Sementara itu untuk perbankan syariah, keharusan pengelolaan risiko ini diatur pada pasal 38-40 Undang-undang Nomor 21 Tahun $2008^{11}$ dan bagi Bank Umum aplikasi manajemen risikonya diatur melalui Peraturan Bank Indonesia Nomor 5/8/PBI/2003.

Manajemen risiko merupakan upaya dalam mengindentifikasi, menganalisis dan mengendalikan risiko pada setiap perusahaan agar perusahaan tersebut berjalan dengan efektif dan efisien. Pada manajemen risiko ini, selain mengidentifikasi perusahaan juga harus mengukur dan menentukan besar-kecilnya risiko yang dihadapi, karena besarkecilnya risiko yang dihadapi akan mempengaruhi pada keputusan yang diambil perusahaan dalam menangani risiko tersebut. ${ }^{12}$

${ }^{10}$ Anjum Iqbal, "Liquidity Risk Management : A Comparative Study between Conventional and Islamic Banks of Pakistan," Global Journal of Management and Business Research 12, no. 5 (2012): 5464.

${ }^{11}$ Rachmadi Usman, Aspek Hukum Perbankan Syari'ah Di Indonesia (Jakarta: Sinar Grafika, 2012).

${ }^{12}$ Misbahul Munir, Implementasi Prudential Banking Dalam Perbankan Syari'ah (Malang: UIN-Malang Press, 2009). 


\section{B. Kajian Pustaka}

Hasil penelitian Faridah Najuna Misman dan M. Ishaq Bhatti mengungkapkan (1) Berdasarkan pendekatan rasio keuangan, BIMB memiliki kinerja yang buruk dibandingkan dengan bank konvensional karena ROA dan ROE mereka berisiko tinggi. (2) Berdasarkan pendekatan analisis saham, saham BIMB berada pada peringkat ke 25 dari 28 saham sektor keuangan yang terdaftar di Bursa Malaysia (berdasarkan rata-rata return), hal ini menunjukkan bahwa risiko saham BIMB lebih tinggi daripada saham lainnya. Dalam ruang lingkup negara Malaysia, bisa dikatakan bahwa risiko yang akan dihadapi bank syariah lebih tinggi daripada bank konvensional.. ${ }^{13}$

Penelitian Obiyathulla Ismath Bacha mengkaji pengaruh interest rate risk terhadap bank Islam. Dua variabel utama yang dikaji pada penelitian ini adalah rate of return dan jumlah total deposito. Dua variabel ini dipilih karena variabel-variabel adalah variabel pertama yang terkena dampak langsung dari perubahan interest rate. Secara umum penelitian ini menggunakan empat variabel, yaitu rate of return 3 bulan deposito bank Islam, ekuivalen, 3 bulan rate of interest yang dibayarkan terhadap deposito fixed, dan total deposito. Penelitian ini menggunakan data bulanan aggregat yang bersumber dari Bank Negara Malaysia (BNM). Penelitian ini menganalisis 113 bulan dari Januari 1994 - Juli 2003. Obiyathulla Ismath Bacha mengungkapkan bahwa bank Islam yang beroperasi dalam dual banking system akan dipengaruhi oleh interest rate risk karena beroperasi berdampingan dengan sistem perbankan konvensional. Hasil lainnya adalah adanya hubungan antara rate of return di bank Islam dengan interest rate bank konvensional karena adanya perbuahan interest rate akan berdampak pada perubahan rate of return bank Islam (berdasarkan Granger Causality Test). ${ }^{14}$

Penelitian Ali Rama dan Salina H. Kasim menemukan bahwa adanya pengaruh signifikan tingkat bagi hasil bank syariah terhadap tingkat deposito dan pembiayaan di bank syariah. Hasil lainnya adalah adanya pengaruh signifikan suku bunga pinjaman bank konvensional terhadap tingkat pembiayaan di bank syariah, artinya adalah

\footnotetext{
${ }^{13}$ Faridah Najuna Misman and M. Ishaq i Bhatt, "Risks Exposure in Islamic Banks: A Case Study of Bank Islam Malaysia Berhad (BIMB)," http://papers.ssrn.com/sol3/papers.cfm?abstract_id=1632849. Diakses pada 10 Oktober 2020

${ }^{14}$ Obiyathulla Ismath Bacha, "Dual Banking System and Interest Rate Risk for Islamic Banks," MPRA Paper No. 12763, 2009, MPRA Pap. No. 12763, http://mpra.ub.unimuenchen.de/12763/1/MPRA_paper_12763.pdf. Diakses tanggal 11 Oktober 2020
} 
pertimbangan nasabah bank syariah dalam menggunakan jasa bank syariah adalah faktor mencari keuntungan, hal ini terlihat dari signifikannya dampak variabel kuangan pada tingkat deposito dan pembiayaan di bank syariah. Temuan ini juga memperkuat faktor eksposur rate of return risk, rate of return risk, dan displaced commercial risk. ${ }^{15}$

Saiful Azhar Rosly dan Mohammad Ashadi Mohd. Zaini menemukan deposito yield dan Return on Equity (ROE) bank syariah tidak mencerminkan sikap risk taking bank syariah, variance bank syariah pun lebih kecil dibandingkan dengan bank konvensional. Temuan praktis dari penelitian ini adalah meningkatnya risk taking pada rekening investasi mudharabah akan meningkatkan return yang diharapkan oleh bank syariah. $^{16}$

Penelitian Zairy Zainol dan Salina H. Kassim menemukan bahwa total deposito bank Islam dan rate of retun bank Islam berhubungan positif yang mengindikasikan risiko rate of retun di bank Islam dimana deposan tertarik dengan rate of retun yang tinggi dan dapat beralih atau menarik deposito mereka ketika rate of return menurun. Pada implementasinya di Malaysia (tempat penelitian ini dilakukan), di mana bank syariah beroperasi bergandengan tangan dengan bank konvensional (dual banking system), kedua sistem dapat berinteraksi mengingat bahwa mereka beroperasi dalam lingkungan ekonomi makro yang umum. Jika rate of return di bank-bank Islam dan suku bunga di konvensional bank dihubungkan, peningkatan suku bunga dapat mendorong bank Islam meningkatkan laba deposito mereka dalam rangka untuk menghindari masalah deposan mengalihkan deposito mereka ke bank-bank konvensional atau menarik dana mereka. Selain itu, tidak ada pembatasan dikenakan pada deposan dalam sistem perbankan ganda di Malaysia yang ingin memindahkan dana mereka dari satu sistem ke sistem lain yang juga bisa mengekspos bank ke masalah Displaced Commercial Risk (DCR). ${ }^{17}$

Heni Hasanah, Noer Azam Achsani, Ascarya dan Hermanto Siregar. Menyatakan bahwa Displaced Commercial Risk terdapat di setiap Dana Pihak Ketiga

${ }^{15}$ Ali Rama and Salina H. Kasim, “Analyzing Determinants of Assets and Liabilities in Islamic Banks: Evidence from Indonesia," Review of Islamic Economics, Finance, and Banking 1, no. 1 (2013): 34-53.

${ }^{16}$ Saiful Azhar Rosly and Mohammad Ashadi Mohd. Zaini, "Risk-Return Analysis of Islamic Banks Investment Deposits and Shareholders Fund," Managerial Finance 34, no. 10 (2008): 695-707.

${ }^{17}$ Zainol and Kassim, “An Analysis of Islamic Bank’s Exposure to Rate of Return Risk." 
bank syariah. Implikasi penting dari penelitian ini bagi manajemen bank syariah adalah agar mengamati fluktuasi interest rate dan faktor-faktor penentu lainnya, dan tidak hanya fokus pada rate of return bank syariah. Hasil lainnya adalah Displaced Commercial Risk terjadi pada nasabah kategori floating customer, maka langkah yang perlu dilakukan bank syariah adalah inovasi produk yang tetap memperhatikan kepatuhan syariah agar loyal customer meningkat. ${ }^{18}$

Penelitian Saiful Anwar dan Kenji Watanabe yang bertujuan mengidentifikasi faktor makroekonomi untuk memaksimalkan pendapatan deposan. Penelitian ini menggunakan teori kebangkrutan, yang menyatakan bahwa probabilitas default dipengaruhi oleh variabel-variabel makroekonomi yang terdiri dari suku bunga, foreign exhange rate, aggregat tabungan, tingkat pertumbuhan, pengeluaran pemerintah, dan tingkat pengangguran. Artinya adalah kemampuan perusahaan memperoleh keuntungan dipengaruhi oleh perubahan kondisi makroekonomi. Variabel-variabel makroekonomi penelitian ini adalah Indeks Saham Jakarta, tingkat inflasi, sertifikat suku bunga bank sentral, nilai tukar rupiah, dan uang beredar. Data yang akan diolah adalah data bulan berjumlah 60 bulan dari Januari 2004 sampai dengan Desember 2008. Karena variabel merupakan data time series non-linear, maka alat analisis yang digunakan adalah model Artificial Neural Network (ANN) dengan menggunakan algoritma propagasi sebagai algoritma pembelajaran. Hasil penelitian menemukan bahwa sertifikat suku bunga bank sentral dan uang beredar bisa digunakan sebagai indikator utama untuk memprediksi rate of return deposan bank syariah di masa mendatang dengan tingkat akurasi $94,95 \%{ }^{19}$

Muhammad Bilal Khalid dan Muhammad Hanif pada penelitian yang dilakukan di 17 bank konvensional dan 2 bank syariah dengan variabel yang diuji pada penelitian ini adalah solvency, capital (asset ratio), equity (asset ratio), Capital Adequacy Ratio (CAR), cost (income), loan (asset). Risiko suku bunga pada penelitian ini diukur dengan analisis GAP untuk mengukur gap antara aset dan liabilitas bank yang sensitif dengan

18 Heni Hasanah and et.al., "Displaced Commercial Risk: Empirical Analysis on The Competition between Conventional and Islamic Banking System in Indonesia," Advances in Natural and Applied Sciences 7, no. 3 (2013): 292-299.

${ }_{19}$ Saiful Anwar and Kenji Watanabe, "Predicting Future Depositor's Rate of Return Applying Neural Network: A Case-Study of Indonesian Islamic Bank," International Journal of Economics and Finance 2, no. 3 (2010). 
suku bunga dan rasio yang sensitif dengan suku bunga dikalkulasi untuk mengukur risiko. Rasio sensitif suku bunga diukur dengan net gap dibagi dengan total aset bank. Risiko kredit pada penelitian ini diukur degan rasio total ekuitas yang dibandingkan dengan cushion of company untuk menyerap risiko kredit. Alat analisis yang dipakai pada penelitian ini adalah analisis GAP, Value at Risk (VAR), dan model Altman. Penelitian ini menemukan risiko likuiditas bank konvensional lebih likuid dan kinerjanya lebih baik daripada bank syariah, dan penelitian ini juga menemukan return bank konvensional lebih tinggi daripada bank syariah walaupun risikonya juga lebih tinggi. ${ }^{20}$

Penelitian Rifki Ismal yang berjudul An Optimal Risk-Retrun Portfolio of Islamic Banks. Tujuan penelitian ini adalah menganalisis instrumen pembiayaan individual dan instrumen portofolio serta menemukan portofolio pembiayaan yang paling efisien. Teori yang digunakan dalam menganalisis masalah penelitian adalah teori risk dan return untuk mengukur risiko dan juga menggunakan teori return dan varians instrumen. Untuk menganalisis portofolio pembiayaan yang paling progresif menggunakan teori kurva efficient portfolio frontier. Variabel-variabel yang diuji pada penelitian ini adalah portofolio pembiayaan murabahah, mudharabah, musyarakah, istishna', actual rate of return, dan expected rate of return. Hasil dari penelitian ini menemukan bahwa perbankan syariah di Indonesia lebih banyak mengalokasikan dananya ke pembiayaan murabahah dan mudharabah, diikuti oleh pembiayaan mudharabah, musyarakah, dan istishna'. Pembiayaan murabahah dan mudharabah memberikan return yang tinggi bagi bank syariah meskipun pembiayaan mudharabah adalah pembiayaan yang sangat berisiko. Kurva efficient portfolio frontier menemukan kombinasi pembiayaan murabahah dan mudharabah adalah pembiayaan yang paling efisien. $^{21}$

Tulisan Zairy Zainol dan Salina Hj. Kassim yang bertujuan untuk mengkritisi literatur rate of return risk bank syariah. Metodologi yang digunakan dalam menyajikan

\footnotetext{
20 Muhammad Khalid, Muhammad Bilal Hanif, "Comparative Risk Return Analysis of Cenventional and Islamic Banks in Pakistan," n.d., http://papers.ssrn.com/sol3 /papers.cfm?abstract_id=2419326. Diakses tanggal 9 Oktober 2020 286-303.

${ }^{21}$ Rifki Ismal, “An Optimal Risk-Return Portfolio of Islamic Banks,” Humanomics 30 (2014):
} 
tulisan ini adalah review literatur menyeluruh. Tulisan ini menemukan bahwa bank syariah masih sensitif terhadap fluktuasi suku bunga perbankan konvensional karena masih banyaknya produk yang syariah yang mengacu pada suku bunga bank konvensional. Keterbatasan teknik dan instrumen yang tersedia untuk mengurangi rate of return risk juga harus mendapatkan perhatian yang lebih bagi para regulator. Tulisan ini juga menyampaikan masih kurangnya penelitian empiris yang mengkaji rate of return risk bank syariah. Implikasi dari tulisan ini juga disampaikan oleh penulis adalah harus ada perhatian khusus melihat dampak rate of return risk bagi stabilitas keuangan dan kinerja perbankan syariah. ${ }^{22}$

Penelitian Seyed-Nezamaddin Makiyan yang mengkaji dinamisasi pinjaman (pembiayaan) dan masalah-masalah yang dihadapi oleh sistem perbankan di Iran. Pembiayaan yang diberikan kepada nasabah bank syariah di Iran dari tahun ke tahun terus meningkat, diantara faktor yang mempengaruhi peningkatan pembiayaan ini adalah rate of return, inflasi, dan intervensi pemerintah. Penelitian ini dilakukan dengan variabel dependen pembiayaan yang disalurkan, sedangkan variabel independen penelitian ini adalah average rate of return, total deposito, dan tingkat inflasi. Alat analisis yang digunakan pada penelitian ini adalah the Dickey-Fuller Unit Root Test untuk menganalisis stasioneritas data, metodologi Johansen digunakan untuk menguji kointegrasi, dan Error Correction Model digunakan untuk menemukan eksogenitas dan endogenitas variabel. Penelitian ini menemukan bahwa intervensi pemerintah yang bertujuan untuk mengelola dana perbankan syariah berperan sangat penting daripada faktor ekonomi (rate of return dan inflasi). ${ }^{23}$

Ginanjar Dewandaru, Obiyathulla Ismath Bacha, A. Mansur M. Masih, dan Rumi Masih pada penelitian mereka mencoba menganalisis karakter risk-return pada indeks syariah dalam rentang waktu yang berbeda melalui analisis wavelet decomposition. Data yang digunakan pada penelitian ini adalah indeks saham syariah dan saham konvensional harian di 11 negara dan 10 sektor global yang terdaftar di Dow

${ }^{22}$ Zairy Zainol and Salina Hj. Kassim, "A Critical Review of The Literature on The Rate of Return Risk in Islamic Banks," Journal of Islamic Accounting and Business Research 3, no. 2 (n.d.): 121137.

23 Seyed-Nezamaddin Makiyan, "Role of Rate of Return on Loans in The Islamic Banking System of Iran," Managerial Finance 29, no. 7 (n.d.): 62-69. 
Jones Islamic Equity Index, data yang diolah adalah data dalam rentang waktu dari tahun 2008 sampai dengan 2012. Variabel yang dianalisis adalah the multi-horizon nature of systemic risk (market beta), rata-rata return, volatilitas dan korelasi. Penelitian ini menemukan bahwa perbedaan beta dan indeks antara syariah dan konvensional pada sebagian besar rentang waktu tidak signifikan secara statistik. Sementara return indeks syariah berisiko lebih rendah dalam skala waktu yang lebih tinggi (longer horizon) di beberapa negara dan enam dari sepuluh sektor global. Penelitian ini juga menemukan korelasi yang rendah beberapa sector-pairs syariah (keuangan, utilitas dan layanan konsumen) pada skala waktu yang lebih rendah (shorter horizons). ${ }^{24}$

Penelitian Raphie Hayat dan Roman Kraeussl menemukan bahwa Islamic Equity Funds performanya berada di bawah benchmark ekuitas konvensional. Namun, performa Islamic Equity Funds terlihat meningkat selama krisis keuangan. Penelitian in juga menemukan manajer Islamic Equity Funds adalah manajer bad market timers karena para manajer mencoba to time the market, namun pada kenyataannya mereka mengurangi return of Islamic Equity Funds, bukan membuat return of Islamic Equity Funds meningkat. Implikasi dari penelitian ini adalah investor muslim bisa meningkatkan performa mereka melalui investasi index tracking funds daripada investasi individu pada Islamic Equity Funds. ${ }^{25}$

\section{Hasil Uji Data dan Pembahasan}

Variabel penelitian ini terdiri dari dua variabel, yaitu variabel dependen (Y) dan variabel indepen (X). Jumlah variabel dependen hanya satu variabel, sedangkan jumlah variabel independen terdapat sebanyak dua variabel. Variabel dependen penelitian ini adalah rate of return risk (risiko imbal hasil) yang terdapat di perbankan syariah di Indonesia. Sedangkan yang menjadi variabel independen pada penelitian ini adalah deposito dan Bank Indonesia Rate. Data penelitian ini diperoleh dari situs resmi Otoritas Jasa Keuangan (OJK) dan Bank Indonesia (BI).

\footnotetext{
${ }^{24}$ Ginanjar d Dewandaru and et.al., "Risk-Return Characteristic of Islamic Equity Indices: MultiTimescales Analysis," Accepted Manuscript Journal of Multinational Financial Management, 2014.

${ }^{25}$ Raphie Hayat and Roman Kraeussl, "Risk and Return Characteristics of Islamic Equity Funds," Emerging Markets Review 12 (2011): 189-203.
} 
| HENDRA CIPTA | Rate of Return RIsk...

Adapun model regresi berganda penelitian ini adalah:

$$
\begin{array}{ll}
Y=\alpha & +b_{1} X_{1}+b_{2} X_{2}+\varepsilon \\
\mathrm{Y} & =\text { Rate of Return Risk (Risiko Imbal Hasil) } \\
\alpha & =\text { Konstanta } \\
\beta_{1}-\beta_{2} & =\text { Koofesien determinasi } \\
\mathrm{X} 1 & =\text { Deposito } \\
\mathrm{X} 2 & =\text { Bank Indonesia Rate } \\
\mathrm{e} & =\text { variabel gangguan }
\end{array}
$$

\section{Hasil Uji Data}

Statistik deskriptif pengolahan data penelitian ini adalah:

Tabel 1. Statistik Deskriptif Data Penelitian

\begin{tabular}{lccc}
\hline \hline & Rate of Return Risk & Deposito & BI Rate \\
Mean & 5257.950 & 176736.1 & 5.662500 \\
Median & 5068.500 & 180748.5 & 5.375000 \\
Maximum & 13372.00 & 231908.0 & 7.500000 \\
Minimum & 588.0000 & 128755.0 & 4.250000 \\
Std. Dev. & 3184.335 & 32971.23 & 1.122596 \\
Skewness & 0.487107 & -0.056696 & 0.538145 \\
Kurtosis & 2.487120 & 1.579241 & 1.989873 \\
& & & \\
Jarque-Bera & 3.030348 & 5.078532 & 5.446890 \\
Probability & 0.219770 & 0.078924 & 0.065648 \\
& & & \\
Sum & 315477.0 & 10604168 & 339.7500 \\
Sum Sq. Dev. & $5.98 \mathrm{E}+08$ & $6.41 \mathrm{E}+10$ & 74.35312 \\
& & & \\
Observations & 60 & 60 & 60 \\
\hline \hline
\end{tabular}

Sumber: Data penelitian diolah

Tabel 1 di atas memperlihatkan nilai mean, median, maximum dan standar deviasi pada tiga variabel yang diuji pada penelitian ini, yaitu rate of return risk, deposito dan BI rate. Melalui hasil pengolahan data pada tabel ini terlihat sampel time series penelitian ini adalah 60 bulan ( 5 tahun) yang terhitung dari bulan Januari 2015 sampai dengan bulan Desember 2019.

Persamaan yang dihasilkan dari regresi pengolahan data penelitian ini sebagai berikut:

\footnotetext{
Rate of Return Risk $=-5570.38818916+0.0529945776759 *$ DEPOSITO + 258.239548448*BI_RATE
} 
Makna dari persamaan regresi ini adalah:

a. Ketika nilai deposito meningkat sebesar $1 \%$, maka nilai rata-rata rate of return risk akan meningkat sejumlah 0.0529945776759.

b. Ketika nilai BI rate meningkat sebesar $1 \%$, maka nilai rata-rata rate of return risk juga akan meningkat sejumlah 258.239548448.

Setelah ditemukan persamaan pada penelitian ini, maka langkah berikutnya dilakukan uji asumsi klasik yang terdiri dari uji normalitas, uji multikolinearitas, uji autokorelasi dan uji heteroskedastisitas. Setelah uji asumsi klasik dilakukan uji hipotesis. Semua uji ini dilakukan dengan menggunakan aplikasi EViews versi 9.

Adapun uji normalitas penelitian ini menghasilkan:

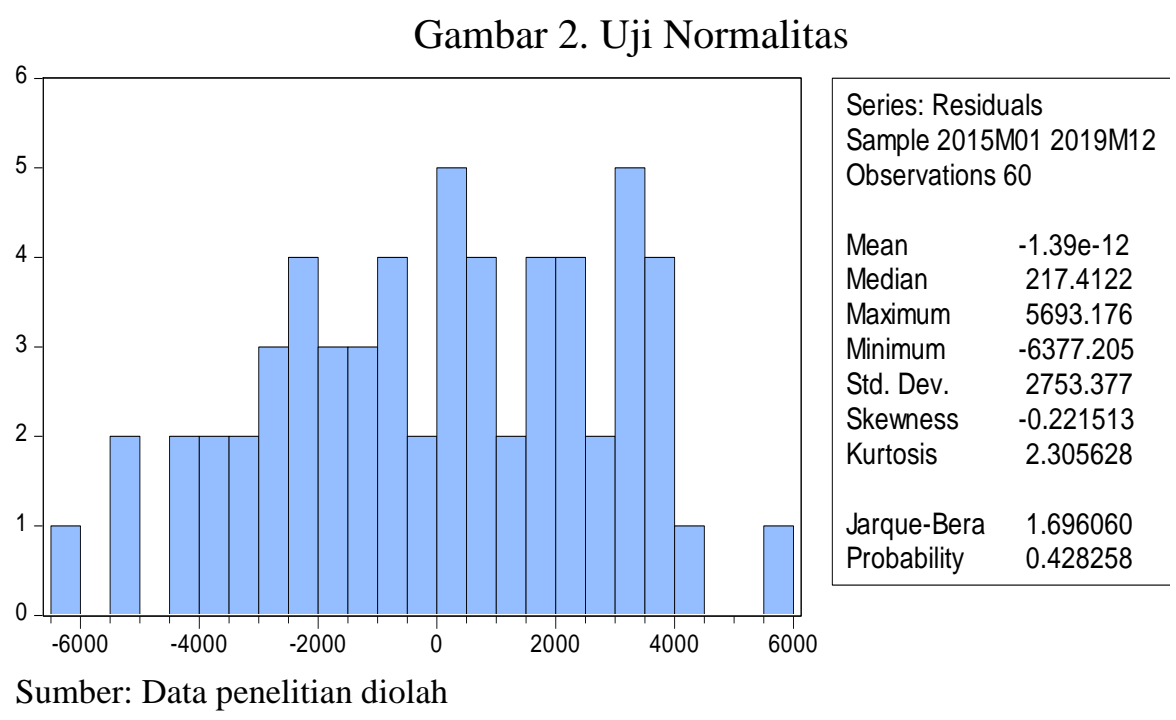

Teori yang digunakan pada uji normalitas ini adalah teori Jarque-Bera dengan kriteria jika nilai Jarque-Bera $<2$ dan nilai probabilitas Jarque-Bera $>5 \%$ maka dinyatakan data berdistribusi normal. ${ }^{26}$ Hasil uji normalitas pada tabel di atas memperlihatkan nilai Jarque-Bera 1,696060 < 2 dan nilai probabilitas Jarque-Bera $0,428258>5 \%$ maka diputuskan data pada penelitian ini sudah berdistribusi normal.

Uji multikolinearitas pada penelitian ini menggunakan teori Variance Inflation Factors (VIF) dengan hasil pengolahan datanya sebagai beirkut:

${ }^{26}$ Wing Wahyu Winarno, Analisis Ekonometrika Dan Statistika Dengan EViews (Yogyakarta: UPP STIM YKPN, 2011). 
Tabel 2. Uji Multikolinearitas

Variance Inflation Factors

Sample: 2015M01 2019M12

Included observations: 60

\begin{tabular}{cccc}
\hline \hline Variable & $\begin{array}{c}\text { Coefficient } \\
\text { Variance }\end{array}$ & $\begin{array}{c}\text { Uncentered } \\
\text { VIF }\end{array}$ & $\begin{array}{c}\text { Centered } \\
\text { VIF }\end{array}$ \\
\hline \hline C & 16904446 & 129.2539 & NA \\
DEPOSITO & 0.000181 & 44.81795 & 1.483057 \\
BI_RATE & 156519.0 & 39.85611 & 1.483057 \\
\hline \hline
\end{tabular}

Sumber: Data penelitian diolah

Penentuan terjadi atau tidaknya multikolinearitas adalah jika nilai VIF $>10$ maka terjadi multikolinearitas. ${ }^{27}$ Nilai VIF variabel deposito dan BI rate yang terdapat pada centered VIF adalah 1,483057 < 10, maka diputuskan tidak terjadi multikolinearitas pada kedua variabel independen penelitian ini.

Uji berikutnya adalah uji autokorelasi, teori yang digunakan pada uji autokorelasi ini adalah Breusch-Godfrey Serial Correlation LM Test dengan kriteria jika nilai probabilitas Obs*R-squared > 5\% maka diputuskan tidak terjadi autokorelasi. Pada hasil uji awal data penelitian ini terjadi autokorelasi karena nilai probabilitas Obs*R-squared $<5 \%$, problem ini diatasi dengan melakukan metode pembedaan umum (generalized differences). ${ }^{28}$ Hasil nya adalah:

Tabel 3. Uji Autokorelasi

Breusch-Godfrey Serial Correlation LM Test:

\begin{tabular}{llll}
\hline \hline F-statistic & 0.171417 & Prob. F(2,54) & 0.8429 \\
Obs*R-squared & 0.372214 & Prob. Chi-Square(2) & 0.8302 \\
\hline \hline Sumber: Data penelitian diolah & &
\end{tabular}

Nilai probabilitas Obs*R-squared (Prob. Chi-Square(2)) penelitian ini adalah $0.8302>5 \%$, maka diputuskan data penelitian ini tidak terjadi masalah pada uji autokorelasi.

${ }^{27}$ Imam Ghozali, Ekonometrika: Teori, Konsep Dan Aplikasi Dengan SPSS 17 (Semarang: Badan Penerbit Universitas Diponegoro, 2011).

${ }^{28}$ Nachrowi D Nachrowi and Hardius Usman, Pendekatan Populer Dan Praktis Ekonometrika Untuk Analisis Ekonomi Dan Keuangan (Jakarta: Lembaga Penerbit Fakultas Ekonomi Universitas Indonesia, 2006). 
Uji terakhir dari uji asumsi klasik ini adalah uji heteroskedastisitas. Teori yang digunakan adalah uji Harvey, ketentuan untuk tidak terjadi masalah heteroskedasdisitas adalah jika nilai probabilitas Obs*R-squared $<5 \%$. ${ }^{29}$ Hasil uji heteroskedastisitas pada penelitian ini adalah:

Tabel 4. Uji Heteroskedastisitas

Heteroskedasticity Test: Harvey

\begin{tabular}{llll}
\hline \hline F-statistic & 1.108551 & Prob. F(2,57) & 0.3370 \\
Obs*R-squared & 2.246415 & Prob. Chi-Square(2) & 0.3252 \\
Scaled explained SS & 2.530474 & Prob. Chi-Square(2) & 0.2822 \\
\hline
\end{tabular}

Sumber: Data penelitian diolah

Nilai probabilitas Obs*R-squared (Prob. Chi-Square(2)) penelitian ini adalah $0,3252<5 \%$, sehingga diputuskan data penelitian ini tidak terjadi masalah heteroskedastisitas. Setelah dilakukan uji asumsi klasik, maka dilakukan uji hipotesis yaitu uji $\mathrm{F}$, uji $\mathrm{T}$ dan uji koefisien determinasi (R2). Hasil uji $\mathrm{F}$ pada data penelitian ini adalah:

\section{Tabel 5. Uji F}

\begin{tabular}{ll}
\multicolumn{1}{c}{ Indikator } & Nilai \\
\hline \hline F-statistic & 9.619838 \\
Prob(F-statistic) & 0.000251 \\
\hline
\end{tabular}

Sumber: Data penelitian diolah

Tabel 5 di atas memperlihatkan nilai probabilitas $\mathrm{F}$ statistik adalah 0,000251 $<5 \%$ atau 0,05. Maka diputuskan variabel deposito dan BI rate secara bersamaan (simultan) berpengaruh terhadap variabel dependen penelitian ini, yaitu rate of return risk.

\section{Tabel 6. Uji T}

Dependent Variable: Rate of Return Risk

Method: Least Squares

Sample: 2015M01 2019M12

Included observations: 60

$$
\text { Variable Coefficient Std. Error t-Statistic Prob. }
$$

${ }^{29}$ Zakaria Firmansyah, “Analisis Pengaruh Umur, Pendidikan, Dan Upah Terhadap Produktivitas Tenaga Kerja," Economics Development Analysis Journal 4, no. 1 (2015): 91-97, https://doi.org/10.15294/edaj.v4i1.14808. 


\begin{tabular}{crrrr}
\hline \hline C & -5570.388 & 4111.502 & -1.354831 & 0.1808 \\
DEPOSITO & 0.052995 & 0.013470 & 3.934227 & 0.0002 \\
BI_RATE & 258.2395 & 395.6248 & 0.652738 & 0.5165 \\
\hline \hline
\end{tabular}

Sumber: Data penelitian diolah

Hasil uji parsial penelitian ini tampak pada tabel 6, dari dua variabel yang diuji terlihat bahwa variabel deposito (X1) secara parsial berpengaruh positif terhadap rate of return risk, dikatakan berpengaruh karena probabilitas $\mathrm{t}$ deposito sebesar $0,0002<0,05(5 \%)$ dan nilai t-statistiknya yang positif $(3,934227)$ mengindikasikan bahwa ketika terjadi peningkatan deposito yang disimpan oleh nasabah pada bank syariah, maka juga akan terjadi peningkatan rate of return risk pada perbankan syariah di Indonesia.

Hasil uji untuk variabel BI rate (X2) secara parsial tidak berpengaruh signifikan terhadap variabel rate of return risk karena probabilitas t variabel BI rate $0,5165>0,05(5 \%)$. Namun hubungan antara BI rate dan rate of return risk ini positif yang terlihat dari nilai t-statistiknya yang positif yaitu 0,652738 .

Uji terakhir pada uji hipotesis ini adalah uji koefisien determinasi (R2) pada tabel berikut ini:

Tabel 7. Uji Koefisien Determinasi (R2)

\begin{tabular}{ll}
\multicolumn{1}{c}{ Indikator } & Nilai \\
\hline \hline R-squared & 0.252358 \\
Adjusted R-squared & 0.226125 \\
\hline \hline
\end{tabular}

Sumber: Data penelitian diolah

Tabel 7 memperlihatkan nilai koefisien determinasi (R2) penelitian ini melalui nilai adjusted $R$-Squared adalah 0,226125 atau 22,6\%. Maksudnya adalah variabel deposito dan BI rate (variabel independen) pada penelitian ini mampu menjelaskan variabel dependen (rate of return risk) sebesar 22,6\%, sedangkan sisanya 77,4\% mampu dijelaskan oleh variabel lain yang tidak dibahas pada penelitian ini.

\section{Pembahasan}

Hasil penelitian ini yang menyatakan bahwa variabel deposito (X1) berpengaruh signifikan positif terhadap rate of return risk perbankan syariah di Indonesia sejalan 
dengan hasil penelitian Zairy Zainol dan Salina H. Kassim yang menyatakan bahwa total deposito bank Islam dan rate of retun bank Islam berhubungan positif ${ }^{30}$, namun hasil penelitian ini berbeda dengan hasil penelitian Saiful Azhar Rosly dan Mohammad Ashadi Mohd. Zaini yang menyatakan deposito yield dan Return on Equity (ROE) bank syariah tidak mencerminkan sikap risk taking bank syariah. ${ }^{31}$ Hasil penelitian ini juga sesuai dengan hasil penelitian Oktariyani Wahyuningtyas yang menemukan bahwa rate of return risk berpengaruh terhadap return Dana Pihak Ketiga Bank Umum Syariah, dimana salahsatu instrumen dari Dana Pihak Ketiga tersebut adalah deposito. ${ }^{32}$

Variabel BI rate (X2) pada hasil penelitian ini tidak berpengaruh terhadap rate of return risk pada bank syariah di Indonesia. Hasil penelitian ini berbeda dengan hasil penelitian Heni Hasanah, Noer Azam Achsani, Ascarya dan Hermanto Siregar yang menyatakan dalam manajemen perbankan syariah perlu juga memperhatikan pergerakan interest rate selain rate of return sebagai faktor yang mempengaruhi Displaced Commercial Risk pada nasabah perbankan syariah. ${ }^{33}$ Hasil penelitian ini juga berbeda dengan penelitian yang dilakukan oleh Saiful Anwar dan Kenji Watanabe yang menyatakan bahwa sertifikat suku bunga bank sentral dan uang beredar bisa digunakan sebagai indikator utama untuk memprediksi rate of return di bank syariah. ${ }^{34}$ Temuan penelitian ini juga berbeda dengan temuan penelitian Zairy Zainol dan Salina Hj. Kassim yang menemukan bahwa bank syariah masih sensitif terhadap fluktuasi suku bunga perbankan konvensional karena masih banyaknya produk yang syariah yang mengacu pada suku bunga bank konvensional. ${ }^{35}$

\footnotetext{
${ }^{30}$ Zainol and Kassim, “An Analysis of Islamic Bank’s Exposure to Rate of Return Risk.”

31 Rosly and Zaini, "Risk-Return Analysis of Islamic Banks Investment Deposits and Shareholders Fund."

32 Wahyuningtyas, "Analisis Pengaruh Risiko Imbal Hasil, Risiko Investasi Dan Risiko Likuiditas Terhadap Return Dana Pihak Ketiga (Studi Pada Bank Umum Syariah).”

${ }^{33}$ Hasanah and et.al., "Displaced Commercial Risk: Empirical Analysis on The Competition between Conventional and Islamic Banking System in Indonesia."

34 Anwar and Watanabe, "Predicting Future Depositor's Rate of Return Applying Neural Network: A Case-Study of Indonesian Islamic Bank."

${ }^{35}$ Zainol and Kassim, "A Critical Review of The Literature on The Rate of Return Risk in Islamic Banks.”
} 
| HENDRA CIPTA | Rate of Return RIsk...

\section{Penutup}

Hasil penguji data yang menghubungkan antara variabel rate of return risk dengan varibel deposito dan BI rate pada Bank Umum Syariah dan Unit Usaha Syariah dari bulan Januari 2015 sampai dengan Desember 2019 di Indonesia menemukan bahwa variabel deposito berpengaruh signifikan positif terhadap munculnya rate of return risk pada bank syariah di Indonesia (khususnya pada Bank Umum Syariah dan Unit Usaha Syariah), hasil penelitian ini sesuai dengan mayoritas hasil penelitian yang sudah dilakukan yang menyatakan bahwa deposito mempunyai peran signfikan terhadap rate of return risk.

Namun, variabel BI rate tidak berpengaruh signfikan terhadap munculnya rate of return risk pada bank syariah di Indonesia. Hasil penelitian ini berbeda dengan kebanyakan penelitian yang sudah dilakukan yang menyatakan bahwa interest rate mempunyai peran terhadap munculnya rate of return risk pada bank syariah. Hasil ini menunjukkan bahwa bank syariah tidak terpengaruh dengan fluktuasi suku bunga yang terjadi karena menggunakan skema profit sharing dan profit margin.

\section{Daftar Pustaka}

Ali, Masyhud. Manajemen Risiko: Strategi Perbankan Dan Dunia Usaha Menghadapi Tantangan Globalisasi Bisnis. Jakarta: PT. Raja Grafindo Persada, 2006.

Anwar, Saiful, and Kenji Watanabe. "Predicting Future Depositor's Rate of Return Applying Neural Network: A Case-Study of Indonesian Islamic Bank." International Journal of Economics and Finance 2, no. 3 (2010).

Bacha, Obiyathulla Ismath. "Dual Banking System and Interest Rate Risk for Islamic Banks." MPRA Paper No. 12763, 2009, MPRA Pap. No. 12763. http://mpra.ub.unimuenchen.de/12763/1/MPRA_paper_12763.pdf. Diakses tanggal 11 Oktober 2020.

Dewandaru, Ginanjar d, and et.al. "Risk-Return Characteristic of Islamic Equity Indices: MultiTimescales Analysis." Accepted Manuscript Journal of Multinational Financial Management, 2014.

Firmansyah, Zakaria. "Analisis Pengaruh Umur, Pendidikan, Dan Upah Terhadap Produktivitas Tenaga Kerja." Economics Development Analysis Journal 4, no. 1 (2015): 91-97. https://doi.org/10.15294/edaj.v4i1.14808.

Ghozali, Imam. Ekonometrika: Teori, Konsep Dan Aplikasi Dengan SPSS 17. Semarang: Badan Penerbit Universitas Diponegoro, 2011.

Greuning, Hennie Van et.al. Risk Analysis for Islamic Banks. Washington: The World Bank, 2008.

Hasanah, Heni, and et.al. "Displaced Commercial Risk: Empirical Analysis on The Competition between Conventional and Islamic Banking System in Indonesia." Advances in Natural and Applied Sciences 7, no. 3 (2013): 292-299.

Hayat, Raphie, and Roman Kraeussl. "Risk and Return Characteristics of Islamic Equity 
Funds.” Emerging Markets Review 12 (2011): 189-203.

https://www.bi.go.id/id/default.aspx

https://www.ojk.go.id/id/Default.aspx.

Iqbal, Anjum. "Liquidity Risk Management: A Comparative Study between Conventional and Islamic Banks of Pakistan." Global Journal of Management and Business Research 12, no. 5 (2012): 54-64.

Ismal, Rifki. "An Optimal Risk-Return Portfolio of Islamic Banks." Humanomics 30 (2014): 286-303.

Khalid, Muhammad Bilal Hanif, Muhammad. "Comparative Risk Return Analysis of Cenventional and Islamic Banks in Pakistan," n.d. http://papers.ssrn.com/sol3/papers.cfm?abstract_id=2419326. Diakses tanggal 9 Oktober 2020.

Khan, Tariqullah. Risk Management: An Analysis of Issuess in Islamic Financial Industry. Jeddah: Lembaga Pelatihan dan Riset Islamic Development Bank, 2001.

Makiyan, Seyed-Nezamaddin. "Role of Rate of Return on Loans in The Islamic Banking System of Iran." Managerial Finance 29, no. 7 (n.d.): 62-69.

Misman, Faridah Najuna, and M. Ishaq i Bhatt. "Risks Exposure in Islamic Banks: A Case Study of Bank Islam Malaysia Berhad (BIMB)," n.d. http://papers.ssrn.com/sol3/papers.cfm?abstract_id=1632849. Diakses pada 10 Oktober 2020.

Munir, Misbahul. Implementasi Prudential Banking Dalam Perbankan Syari'ah. Malang: UINMalang Press, 2009.

Nachrowi, Nachrowi D, and Hardius Usman. Pendekatan Populer Dan Praktis Ekonometrika Untuk Analisis Ekonomi Dan Keuangan. Jakarta: Lembaga Penerbit Fakultas Ekonomi Universitas Indonesia, 2006.

Rama, Ali, and Salina H. Kasim. "Analyzing Determinants of Assets and Liabilities in Islamic Banks: Evidence from Indonesia." Review of Islamic Economics, Finance, and Banking 1, no. 1 (2013): 34-53.

Rosly, Saiful Azhar, and Mohammad Ashadi Mohd. Zaini. "Risk-Return Analysis of Islamic Banks Investment Deposits and Shareholders Fund." Managerial Finance 34, no. 10 (2008): 695-707.

Sholihin, Ahmad Ifham. Buku Pintar Ekonomi Syari'ah. Jakarta: PT. Gramedia Pustaka Utama, 2010.

Usman, Rachmadi. Aspek Hukum Perbankan Syari'ah Di Indonesia. Jakarta: Sinar Grafika, 2012.

Wahyudi, Imam, and et.al. Manajemen Risiko Bank Islam. Jakarta: Salemba Empat, 2013.

Wahyuningtyas, Oktariyani. "Analisis Pengaruh Risiko Imbal Hasil, Risiko Investasi Dan Risiko Likuiditas Terhadap Return Dana Pihak Ketiga (Studi Pada Bank Umum Syariah).” Fakultas Ekonomi Dan Bisnis Islam UIN Sunan Kalijaga Yogyakarta, 2017.

Winarno, Wing Wahyu. Analisis Ekonometrika Dan Statistika Dengan EViews. Yogyakarta: UPP STIM YKPN, 2011.

Zainol, Zairy, and Salina H. Kassim. "An Analysis of Islamic Bank's Exposure to Rate of Return Risk." Journal of Economic Cooperation and Development 31, no. 1 (2010): 5984.

Zainol, Zairy, and Salina Hj. Kassim. "A Critical Review of The Literature on The Rate of Return Risk in Islamic Banks." Journal of Islamic Accounting and Business Research 3, no. 2 (n.d.): $121-137$. 